\section{Commentary: Hyperlactatemia after cardiac surgery: Yes we know it is bad but can we reliably prevent and treat it?}

\author{
Shuab Omer, MD
}

Hyperlactatemia (HL) is associated with increased mortality and morbidity after cardiac surgery ${ }^{1,2}$ and is widely considered a useful marker of tissue hypoxia. However, it is worth appreciating that the lactate metabolism during the perioperative period is complex, dynamic, and incompletely understood. In addition, the causes of perioperative hyperlactatemia are diverse, including both hypoxic and nonhypoxic etiologies. ${ }^{1,3}$

In this issue of JTCVS Techniques, Condello et $\mathrm{al}^{4}$ have compared the effect of 2 global parameters of oxygen delivery: 1) indexed oxygen delivery $\left(\mathrm{DO}_{2} \mathrm{i}\right)$ in relation to the indexed oxygen extraction ratio $\left(\mathrm{O}_{2} \mathrm{ERi}\right)($ group $\mathrm{A})$; and 2$)$ the cardiac index $(\mathrm{CI})$ in relation to the mixed venous oxygen saturation $\left(\mathrm{SvO}_{2}\right)$ (group B) on hyperlactatemia during cardiopulmonary bypass (CPB). They concluded that the management of $\mathrm{DO}_{2} \mathrm{i}$ in relation to the $\mathrm{O}_{2} \mathrm{ERi}$ was $16 \%$ more specific in terms of the negative predictive value for HL during CPB compared with the use of the $\mathrm{CI}$ in relation to the $\mathrm{SvO}_{2}{ }^{4}$ Interestingly, they also reported a significant reduction in the incidence of the intraoperative lactate peak, which correlated with a postoperative reduction in the serum creatinine value, mechanical ventilation time, and intensive care unit stay, in favor of group A compared with group B. ${ }^{4}$

From the Department of Advanced Cardiopulmonary Therapies and Transplantation, The University of Texas Health Science Center at Houston, McGovern Medical School, Houston, Tex.

Disclosures: The author reported no conflicts of interest.

The Journal policy requires editors and reviewers to disclose conflicts of interest and to decline handling or reviewing manuscripts for which they may have a conflict of interest. The editors and reviewers of this article have no conflicts of interest.

Received for publication March 5, 2020; revisions received March 5, 2020; accepted for publication March 8, 2020; available ahead of print April 11, 2020.

Address for reprints: Shuab Omer, MD, Department of Advanced Cardiopulmonary Therapies and Transplantation, The University of Texas Health Science Center at Houston, McGovern Medical School, Houston, TX 77030 (E-mail: shuab.omer@ uth.tmc.edu).

JTCVS Techniques 2020;2:102-3

2666-2507

Copyright $@ 2020$ The Authors. Published by Elsevier Inc. on behalf of The American Association for Thoracic Surgery. This is an open access article under the CC BY-NCND license (http://creativecommons.org/licenses/by-nc-nd/4.0/).

https://doi.org/10.1016/j.xjtc.2020.03.035

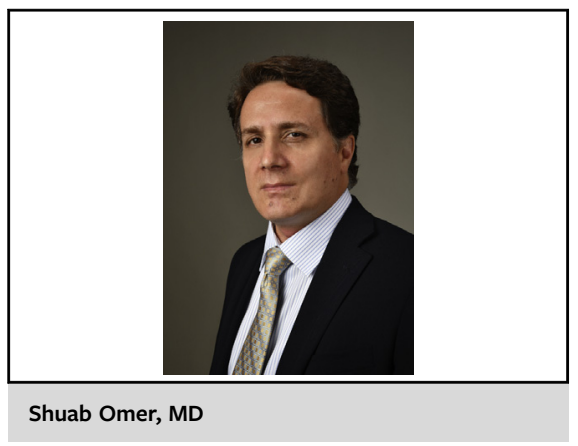

\begin{abstract}
CENTRAL MESSAGE
Although $\mathrm{DO}_{2}$ i in relation to

$\mathrm{O}_{2}$ ERi appears to be more spe-

cific regarding the negative pre-

dictive value of hyperlactatemia

compared with traditional in-

dexes such as $\mathrm{Cl}$ and $\mathrm{SvO}_{2}$ and

hyperlactatemia is a marker of

poor tissue perfusion, it is un-

clear whether optimization of

global indexes of oxygen delivery

alone can reliably prevent or help

in treating hyperlactatemia in

patients undergoing CPB.
\end{abstract}

Although the authors have demonstrated an improved negative predictive value for $\mathrm{HL}$ using $\mathrm{DO}_{2} \mathrm{i}$ in relation to $\mathrm{O}_{2} \mathrm{ERi}$, it is worth appreciating that $\mathrm{CPB}$ and cardiac surgery are associated with deleterious effects on the microcirculation. ${ }^{5}$ A fundamental feature of such adverse microcirculatory physiology is that, despite normalization or optimization of the global indexes of oxygen delivery (eg, cardiac output, $\mathrm{SvO}_{2}$ ) with fluid and inotrope therapy, restoration of microcirculatory flow is lacking, akin to septic shock physiology. This lack of microcirculatory flow despite optimal global indexes of oxygen delivery have been variously attributed to vasoconstriction, altered red blood cell deformity, activation of platelets, and the coagulation cascade. ${ }^{6}$ Furthermore, it is important to appreciate that an uncoupling of global and regional tissue/cellular level oxygen delivery is likely during CPB. Thus, attempting to augment oxygen delivery solely using the $\mathrm{DO}_{2} \mathrm{i}$ or CI might not reliably restore microvascular flow and, thus, 
would not consistently treat tissue and/or cellular level hypoxia.

It is also very important to appreciate that during cardiac surgery, the total time of CPB is only 1 segment of the total operative time and that both the pre- and post-pump periods are, essentially, equally important determinants of overall patient outcomes. Although they have done a great job in carefully documenting the global indexes of oxygen delivery during $\mathrm{CPB}$, they provided no further information about the pre- and post-CPB period or in the intensive care unit. For example, a patient could go into cardiogenic shock after $\mathrm{CPB}$ despite having great indexes during $\mathrm{CPB}$. Their study did not account for such common pre- and post-pump scenarios, which weakens the conclusions drawn with regard to the outcomes. To be more meaningful, hard outcome data, such as mortality, morbidity, and survival, should have been included.

In conclusion, although the $\mathrm{DO}_{2} \mathrm{i}$ in relation to the $\mathrm{O}_{2}$ ERi appears to be more specific with regard to the negative predictive value for hyperlactatemia compared with traditional indexes such as $\mathrm{CI}$ and $\mathrm{SvO}_{2}$ and it is well established that hyperlactatemia is a marker of poor tissue perfusion, it is unclear whether optimization of the global indexes of oxygen delivery alone can reliably prevent or help in treating hyperlactatemia in patients undergoing CPB.

\section{References}

1. O'Connor E, Fraser JF. The interpretation of perioperative lactate abnormalities in patients undergoing cardiac surgery. Anaesth Intensive Care. 2012;40:598-603.

2. Ranucci M, De Toffol B, Isgro G, Romitti F, Conti D, Vicentini M. Hyperlactatemia during cardiopulmonary bypass: determinants and impact on postoperative outcome. Crit Care. 2006;10:R167.

3. Gladden LB. Lactate metabolism: a new paradigm for the third millennium. $J$ Physiol. 2004;558:5-30.

4. Condello I, Santarpino G, Nasso G, Moscarelli M, Fiore F, Speziale G. Associations between oxygen delivery and cardiac index with hyperlactatemia during cardiopulmonary bypass. J Thorac Cardiovasc Surg Tech. 2020;2:92-9.

5. Koning NJ, Atasever B, Vonk AB, Boer C. Changes in microcirculatory perfusion and oxygenation during cardiac surgery with or without cardiopulmonary bypass. J Cardiothorac Vasc Anesth. 2014:28:1331-40.

6. Minton J, Sidebotham DA. Hyperlactatemia and cardiac surgery. J Extra Corpor Technol. 2017:49:7-15. 